\title{
DESAFIOS PARA A EDUCAÇÃO ESCOLAR ESPECÍFICA EM CONTEXTOS DE POLÍTICAS UNIVERSALIZANTES
}

\author{
Clovis Antonio Brighenti ${ }^{*}$
}

\begin{abstract}
Resumo
Neste artigo, desenvolvemos uma análise crítica do sistema de ensino no que tange às políticas universalizantes e os desafios para a educação escolar específica e diferenciada conquistada pelos povos indígenas. Na medida em que esses direitos específicos foram sendo alargados e tornados realidade, o Ministério da Educação criou diversos mecanismos que circulam na contramão, valorizando e exigindo conhecimento de saberes ditos universais. Como exemplo, tomamos os dados colhidos junto ao Indice de Desenvolvimento da Educação Básica (Ideb) relativos à avaliação das escolas indígenas em Santa Catarina nos anos de 2011 e de 2013 e constatamos que as mesmas ficaram entre as piores colocações no estado. Buscamos, então, compreender a metodologia e a ideologia que orientaram as avaliações, do que percebemos que há a imposição de conteúdos e de práticas metodológicas. A avaliação, sem respeitar suas particularidades, segue sendo uma maneira de impor aos indígenas a integração à "nação" brasileira. A partir dos conceitos de colonialidade, concluímos que, ao persistir esse modelo de avaliação, as notas baixas servirão como formas de resistência.
\end{abstract}

Palavras-chave: Educação escolar. Avaliação. Resistência.

* Doutor em História Cultural pelo Programa de Pós Graduação em História (PPGH) da Universidade Federal de Santa Catarina (UFSC). Professor de História Indígena na Universidade Federal da Integração Latino-Americana (UNILA). E-mail:clovisbrighenti@hotmail.com 


\section{Introdução}

A substituição dos vestibulares pelas provas do Exame Nacional do Ensino Médio (Enem) é considerada uma etapa superior de avanços rumo à construção de maior unidade no sistema de ensino e no acesso ao Ensino Superior. Se tomarmos os modelos dos vestibulares específicos em cada universidade, com suas particularidades e datas distintas, podemos dizer que sim, que, do ponto de vista metodológico e político, o Enem representa um avanço, ${ }^{1}$ afinal, com sua adoção, qualquer interessado poderá fazer a prova o mais próximo de sua casa e, a partir de sua nota final, escolher o curso e a universidade em que deseja estudar.

Esse cenário nos faz pensar nas populações que, pelo direito conquistado, tiveram a possibilidade de criar outros sistemas de educação básica ou que não vivem em contextos urbanos a partir dos quais os temas do Enem são pensados. Em nossos trabalhos junto a comunidades indígenas, a fim de auxiliar seus estudantes na preparação para as provas do Enem, percebemos o quanto o conteúdo da prova está distante da vivência escolar e cotidiana destes. A redação, de maneira particular, é, sem dúvida, o maior desafio para essas sociedades, que têm na oralidade sua principal forma de transmissão de conhecimentos. Nesse cenário, muitas universidades vêm adotando outros mecanismos de ingresso, como provas de seleção com conteúdos específicos ou mesmo vestibulares específicos. Com isso, fica patente o quanto o Enem pode ser um processo de seleção que cumpre uma função importante, mas que não contempla a diversidade de contextos.

Outra novidade que vem sendo amplamente discutida pela sociedade, em maior ou menor grau, é a Base Nacional Comum Curricular (BNCC) para a educação básica. $\mathrm{Na}$ segunda versão da proposta preliminar lançada pelo Ministério da Educação (MEC), em 2016, consta que a BNCC "é uma exigência colocada para o sistema educacional brasileiro pela Lei de Diretrizes e Bases da Educação Nacional (BRASIL, 1996; 2013), pelas Diretrizes Curriculares Nacionais Gerais
1 Nem todas as universidades usam como critério único de ingresso as provas do Enem, havendo, assim, um misto entre a exclusividade do Enem, o aproveitamento no Enem e do vestibular e a adoção somente do vestibular. 

de Educação (BRASIL, 2014)" (BRASIL, 2016b, p. 24). A construção de uma Base Comum é apresentada como um avanço que elevará a qualidade da educação. Além disso, essa proposta é apresenta como um elemento fundamental para nortear um projeto de nação. Sem entrar no mérito dos temas abordados e da forma como serão aplicados os conteúdos, salta aos olhos como os legisladores da BNCC desejam a criação de uma identidade nacional a partir de tal projeto. É importante observar que o Brasil, a partir do Estado, continua sendo pensado e proposto a partir do projeto de nação, de forma que a plurinacionalidade que se expressa nos mais diferentes contextos e regiões do Brasil se moldar a esse projeto nacionalizante. É difícil perceber se essa tendência é uma retomada dos ideais de nação do século XIX ou um aprofundamento da lógica neoliberal, em que os discursos são de pluralidade, inclusão e interdisciplinaridade e as práticas estão justamente no sentido contrário, ou seja, o de transformar sujeitos em massa consumidora.

Um terceiro elemento que contraria as práticas de educação escolar específica é a avaliação da educação básica. Esse mecanismo talvez seja o mais perverso em contrariar a educação que tem em seu horizonte a valorização de saberes específicos dos povos, porque ele é aplicado em todas as escolas, independentemente do local e do conteúdo ministrado, e porque valoriza apenas dois conteúdos: português e matemática. Por que todos os jovens e crianças precisam saber português e matemática em detrimento de outros conteúdos? Por que alguém definiu que esses são os conteúdos mais importantes para a educação escolar?

Ao longo deste nosso artigo, tentaremos buscar entender melhor esses temas à luz das reflexões sobre a educação escolar indígena.

\section{A conquista da escola específica e diferenciada}

A conquista mais expressiva dos povos indígenas no Brasil, nas últimas décadas - talvez desde a invasão portuguesa 
-, foi a aprovação do texto constitucional de 1988. Longe de ser um marco jurídico extremamente avançado, como necessitam e desejam os povos indígenas, ele se caracterizou por alterar profundamente o passado colonial, as políticas de branqueamento do século XIX e os ideais do nacionalismo do século XX. Dois aspectos se sobressaem nesse rompimento com a colonialidade: o primeiro deles tem a ver com a possibilidade de os indígenas participarem ativamente na construção de suas pautas com o fim do regime tutelar (Art. 231 e 232). A tutela se manifestava de maneira distinta nas diferentes regiões do Brasil e era mais percebida nos contextos de extrações de produtos naturais com fins econômicos para compor a rubrica contábil dos órgãos indigenistas federais, denominada "renda indígena", como madeira, garimpo, lavouras mecanizadas, criação de gado e arrendamentos de terra. A exploração desses recursos naturais ocorria mediante a repressão aos indígenas, a fim de mantê-los controlados para não contrariarem as políticas do Estado e os desvios de verbas por parte de seus servidores. O fim da tutela significou a permissão para os povos indígenas se manifestarem livremente, defender seus direitos e decidir seus projetos históricos, além da possibilidade de criarem associações civis.

Outra mudança profunda introduzida com a Constituição Federal de 1988 foi a modificação do conceito de educação escolar (Art.210). Ainda que de maneira tímida, a CF garantiu o direito à "utilização de suas próprias línguas maternas e processos próprios de aprendizagem” (BRASIL, 1988). Dois aspectos se sobressaem, quais sejam o uso das línguas maternas e as formas próprias de transmitir os conhecimentos. No caput do artigo também está assegurado o respeito aos valores culturais. Essas garantias abriram as portas para as conquistas que viriam a seguir com a legislação infraconstitucional, as quais foram sendo buriladas com a participação ativa dos povos indígenas.

Da legislação infraconstitucional, destacamos apenas alguns elementos que nos auxiliam na compreensão da extensão dos direitos da educação escolar específica e 
diferenciada. Da Lei de Diretrizes e Bases da Educação Nacional (LDB), de 1996, destacamos o Art. 78 por afirmar a interculturalidade e o bilinguismo nas escolas indígenas como elementos fundamentais para a reafirmação de suas identidades, valorização da memória histórica e da ciência própria e incentivo do uso da língua materna no diálogo crítico com os conhecimentos ocidentais. O Art. 79 determina à União o apoio técnico e financeiro para gestão do sistema de ensino desenvolvido pelos estados e/ou municípios, aplicando programas integrados de ensino e pesquisa, planejados com anuência das comunidades indígenas. Nele, garante-se também o desenvolvimento de currículos e de programas específicos, neles incluindo conteúdos culturais correspondentes às respectivas comunidades e o apoio para a publicação de material didático específico e diferenciado (BRASIL, 1996).

O Referencial Curricular Nacional para as Escolas Indígenas (RCNEI), de 1998, publicado pelo Ministério da Educação, oferece subsídios para a elaboração de projetos pedagógicos para as escolas indígenas (BRASIL, 1998). Esse é um documento importante, muito embora tenha limitações conceituais, como apontam Borges e Borges:

A proposta historiográfica contida no Referencial traz problemas em sua essência, seu pressuposto teórico limita a formação de um agente histórico transformador, comprometendo a discussão da história como prática social dos homens. Não se trata de rejeitar a proposta de um Referencial, pois, sua publicação teve um efeito benéfico junto aos órgãos de ensino estaduais e municipais ao colocar a educação escolar indígena de forma concreta e oficial, porém, é necessário que saibamos quais suas limitações e decorrências para os projetos históricos das Comunidades indígenas (BORGES; BORGES, [20]--].

Um terceiro ordenamento que merece destaque é o Parecer no 14/99 do Conselho Nacional de Educação, pelo qual ficam estabelecidas as Diretrizes Curriculares Nacionais da Educação Escolar Indígena, criando a categoria Escola Indígena no sistema de ensino do país com a finalidade de que 
sejam verdadeiramente específicas e interculturais (BRASIL, 1999a). A criação dessa categoria permite autonomia das escolas tanto no aspecto pedagógico como no financeiro, garantindo aos povos indígenas maior autonomia na gestão escolar. O referido parecer foi transformado em ordenamento jurídico através da Resolução no 03/99 do Conselho Nacional de Educação (BRASIL, 1999b).

Agregamos à legislação nacional a internacional, especialmente a Convenção $n^{\text {o }} 169$ da Organização Internacional do Trabalho (OIT), à qual o Brasil é signatário, pois a mesma confere aos povos indígenas o direito a uma educação escolar específica e diferenciada. Ela também determina que os povos indígenas não precisam seguir as orientações nacionais quanto ao calendário, à alfabetização e aos horários de funcionamento da escola, bem como possuem a liberdade de definir os conteúdos curriculares que desejam dar mais ênfase em seu processo de ensino (BRASIL, 2002).

Essas garantias legais representaram algo inédito na relação entre os povos indígenas e a sociedade nacional, pois elas rompem com um passado de imposições de saberes, de domesticação, de mudanças profundas que se pretendia para esses povos, integrando-os à "nação" brasileira. A escola como projeto colonial era o principal instrumento e agente externo encarregado de alterar profundamente os saberes e as práticas desses povos, impondo-lhes outros saberes, vazios de significados, mas responsáveis por novas cosmografias, na perspectiva da construção de "um projeto educativo para a formação do cidadão imbuído de uma identidade nacional" (BERGAMASCHI, 2010, p.134).

Visualiza-se, neste momento, um novo cenário e se projeta, sobre essas novas experiências de educação escolar, um horizonte de renovação da educação escolar brasileira, que doravante deverá adotar a perspectiva do diálogo intercultural.

\section{Aavaliaçãodoensino comotendênciaà uniformização}

Em um olhar mais atento ao conjunto dos ordenamentos jurídicos da educação nacional, percebe-se que as 
especificidades da educação escolar indígena ficam seriamente prejudicadas ou mesmo ameaçadas de ocorrer por conta de um pensamento universalizante e, portanto, destinado a todas as unidades e níveis de ensino. Identificamos, na política e na legislação da avaliação escolar, um dos principais elementos de sobreposição dos conceitos universalizantes sobre as especificidades.

Com o argumento de melhorar a educação básica, o governo criou mecanismos para avaliação unificados nacionalmente. A fim de melhor compreender o processo de criação do sistema escolar, buscamos o auxílio da análise de Silva (2010, p.429):

O sistema de avaliação brasileiro foi se ampliando e se complexificando desde o fim da década de 1980 até o atual contexto. Segundo Bonamino e Franco (1999), em 1988 o então criado Sistema Nacional de Avaliação do Ensino Público de $1^{\circ}$ Grau (Saep/MEC) realiza uma aplicação piloto nos Estados do Paraná e Rio Grande do Norte, com a intenção de testar instrumentos e procedimentos. Entretanto, a falta de recursos impediu o prosseguimento do projeto, deslanchando efetivamente a partir de 1990 , com a viabilização do primeiro ciclo do Sistema Nacional de Avaliação da Educação Básica (Saeb). Na sequência, os ciclos de avaliação se davam por amostragem, trianualmente. A partir de 2001, ocorre uma mobilização do MEC no sentido de empreender um rigoroso planejamento no funcionamento do Saeb, sendo repaginado e aprimorado. Em 2005, é novamente aperfeiçoado, ampliando-se com a inclusão da Prova Brasil, tendo, entre outras mudanças, uma avaliação em larga escala de caráter universal com aplicação bianual.

Se as escolas indígenas são específicas e diferenciadas e cada povo tem uma forma própria de conceber sua escola, os indicadores de avaliação devem estar contidos no projeto político-pedagógico (PPP) da escola. É a comunidade escolar que deve decidir o que e como avaliar. Não entanto, para o MEC, essa possibilidade não substitui o processo nacional.

Em 2005, através Portaria no 931 (BRASIL, 2005), foi criado o Sistema Nacional de Avaliação da Educação 
Básica (Saeb). Em 2016, o Saeb foi incorporado pelo Sistema

Nacional de Avaliação da Educação Básica (Sinaeb), o qual é composto pela Avaliação Nacional da Educação Básica (Aneb) - conhecida ainda pela antiga sigla, Saeb - e pela Avaliação Nacional do Rendimento Escolar (Anresc) - mais conhecida como e pela Prova Brasil (BRASIL, 2016a). A última etapa da educação básica é avaliada por meio do Exame Nacional do Ensino Médio (Enem). O ensino superior é avaliado pelo Sistema Nacional de Avaliação da Educação Superior (Sinaes) por meio do Exame Nacional de Desempenho dos Estudantes (Enade), dentre outros instrumentos.

De acordo com o portal do MEC na internet (BRASIL, 2016c), as avaliações da aprendizagem são coordenadas pelo Instituto Nacional de Estudos e Pesquisas Educacionais Anísio Teixeira - Inep. O Inep é uma autarquia federal vinculada ao Ministério da Educação e foireestruturado em 2007. Sua missão

[...] é promover estudos, pesquisas e avaliações sobre o Sistema Educacional Brasileiro com o objetivo de subsidiar a formulação e implementação de políticas públicas para a área educacional a partir de parâmetros de qualidade e equidade, bem como produzir informações claras e confiáveis aos gestores, pesquisadores, educadores e público em geral (BRASIL, 2007b).

Em 2007, o Inep criou um Ideb indicando dois conceitos considerados importantes para a qualidade da educação: aprovação e média de desempenho dos estudantes em língua portuguesa e em matemática. $\mathrm{O}$ indicador é calculado a partir dos dados sobre aprovação escolar obtidos no Censo escolar (BRASIL, 2007a) e das médias de desempenho nas avaliações do Inep, o Saeb e a Prova Brasil.

A Portaria no 369 (BRASIL, 2016a), que criou o Sinaeb, incorporou outros elementos à avaliação do desempenho escolar, mas os princípios norteadores do processo de avaliação continuam sendo os mesmos. Pelo Art. $8^{\circ}$ dessa portaria, ficam definidos, no âmbito do Sinaeb: a) Avaliação Nacional 
da Educação Infantil, com ciclo avaliativo bianual, a iniciarse em 2017; b) Avaliação de Alfabetização, "Provinha Brasil", disponibilizada pelo Inep, no início e no final de cada ano letivo, para uso das escolas das redes pública e privada de ensino que manifestarem interesse, com o objetivo principal de auxiliar o professor a avaliar o nível de alfabetização dos educandos no $2^{\circ}$ ano do Ensino Fundamental; e c) Avaliação Nacional de Alfabetização, de aplicação bianual, com o objetivo de avaliar a alfabetização e o letramento em língua portuguesa e a alfabetização em matemática dos educandos do $3^{\circ}$ ano do Ensino Fundamental (BRASIL, 2016a).

Seja nas legislações anteriores, seja no Sinaeb, não encontramos qualquer referência à possibilidade de avaliações diferenciadas para escolas específicas, tampouco sobre outros conteúdos a serem avaliados. As escolas indígenas, para obtenção de boa nota junto ao Ideb, precisam ensinar português e matemática em seus processos de aprendizagem, seguindo uma padronização que há em todos os níveis de ensino, como muito bem pontuou Silva:

Atualmente, todas as etapas e níveis de ensino, exceto a educação infantil, sofrem avaliação padronizada, organizada e centralizada pelo Instituto Nacional de Estudos e Pesquisas Educacionais Anísio Teixeira (Inep) órgão ligado ao Ministério da Educação e Cultura (MEC). O destaque premente nos resultados do Sistema Nacional de Avaliação da Educação Básica (Saeb) [substituído pelo Sinaeb em 2016] é do Índice de Desenvolvimento da Educação Básica (Ideb) que, por meio de acordos e convênios intergovernamentais, têm instigado a curiosidade de pesquisadores da área acerca do seu funcionamento, mecanismos, relevância e implicações na política educacional brasileira (SILVA, 2010, p.429).

A padronizaçãoé, sem sombra de dúvidas,o maior desafio para aqueles setores da sociedade que desejam não apenas estabelecer educação diferenciada, mas inovar no sentido de despertar nas crianças e nos jovens outras habilidades que não seja apenas aprender português e matemática. A escola, 
porém, no atual contexto, passa a ser apenas uma reprodutora de saberes, desestimulando a criatividade, a competência e a pluralidade.

\section{Avaliação das escolas indígenas em Santa Catarina pelo Ideb}

$\mathrm{Na}$ divulgação dos dados das avaliações do Ideb realizadas nos anos de 2011 e de 2013 no estado de Santa Catarina, foram listadas todas as escolas avaliadas. Dentre elas, constam pelo menos três escolas indígenas, uma do povo Xokleng Laklãnõ e duas do povo Kaingang. Os dados da avaliação dos anos iniciais ${ }^{2}$ para 2011 colocaram a Escola Indígena de Educação Básica (EIEB) Cacique Vanhkre em último lugar, com nota 3,1; a Escola Indígena de Ensino Fundamental (EIEF) Pinhalzinho, também do povo Kaingang na mesma Terra Indígena), teve nota 3,5 ficando apenas quatro colocações acima da Vanhkre. A Escola Indígena de Educação Básica EIEB Laklãnõ ficou com 4,5.

No ano de 2013, as notas seguiam baixas: 3,2 para a EIEB Cacique Vanhkre; 2,9 para a EIEF Pinhalzinho; e 3,5 para a EIEB Laklãnõ. Foram mais baixas, portanto, as notas em relação à avaliação anterior.

Quadro 1 - Resultado dos anos iniciais (4ª série ou $5^{\circ}$ ano)

\begin{tabular}{|l|l|l|}
\hline Escola & & \\
\hline EIEB Cacique Vanhkre & 3,1 & 3,2 \\
\hline EIEF Pinhalzinho & 3,4 & 2,9 \\
\hline EIEB Laklãnõ & 4,5 & 3,5 \\
\hline Média no estado de SC & 5,7 & 5,7 \\
\hline
\end{tabular}

Fonte: BRASIL/MEC/INEP (2014)

$\mathrm{Na}$ avaliação dos anos finais do Ensino Fundamental (8a série ou $9^{\circ}$ ano), a EIEB Cacique Vanhkre aparece novamente em última colocação no estado, com nota 2,3 em 2011 e 2,2 em 2013. ${ }^{3}$ A EIEB Laklãnõ recebeu nota de 2,8 em 2011 (ficando duas posições acima da Vanhkre) e 3,2 em 2013.
2 As avaliações do Ensino Fundamental nas escolas indígenas foram realizadas apenas nos anos de 2011 e de 2013. Nos demais anos, as escolas não participaram ou não foram divulgados os dados.
3 A EIEF Pinhalzinho não participou ou os dados em relaçáo aos anos finais do Ensino Fundamental não foram divulgados. 
Quadro 2 - Resultado dos anos finais (8a série ou 9o ano)

\begin{tabular}{|l|c|c|}
\hline Escola & & \\
\hline EIEB Cacique Vanhkre & 2,3 & 2,2 \\
\hline EIEF Pinhalzinho & -- & -- \\
\hline EIEB Laklãnõ & 2,8 & 3,2 \\
\hline Média no estado de SC & 4,7 & 4,1 \\
\hline
\end{tabular}

Fonte: BRASIL/MEC/INEP (2014).

A natureza desse ordenamento provoca constrangimento nas escolas, pois elas não conseguem atingir os índices de "aproveitamento", fazendo com que professores e alunos indígenas sintam-se retraídos e impotentes diante da comparação dos resultados em nível estadual ou mesmo regional. Disso resulta que, para a sociedade regional, as notas baixas indicam que está havendo incompetência dos gestores e dos professores dessas escolas em desenvolver ativamente o processo de ensino. As notas interferem também nas decisões dos pais em matricular os filhos na escola, tornando comum, nos contextos relatados, encontrar famílias que buscam escolas fora das Terras Indígenas para matricular seus filhos, muito vezes com sacrifícios econômicos e não poucas vezes submetendo seus filhos a uma série de preconceitos. Ou seja, tais avaliações, ao invés de ser um processo educativo, tornamse manipuladoras e provocadoras de tensões sociais.

\section{Uma prática de resistência ao projeto homogeneizador}

Perante a sociedade nacional, os dados anteriores, que colocam as escolas indígenas em último lugar no Índice de Desenvolvimento da Educação Brasileira, dão ao ensino do estado de Santa Catarina um cunho extremamente negativo. Porém, pensando a partir da ótica do universal e do específico, podemos ler os dados a partir de outro ângulo e perceber que, ao menos, as escolas indígenas estão se diferenciado do sistema de ensino daquele estado, ou seja, não estão seguindo os parâmetros de ensino considerados relevantes para a sociedade nacional. 
É verdade que esses dados carecem de uma avaliação mais aprofundada no seu universo micro, ou seja, a partir especificamente dos contextos escolares, mas, para efeito de nossa análise, esses dados nos auxiliam a perceber que esse sistema de avaliação nacional e unificado não contempla a educação diferenciada. O Sinaeb parte do pressuposto de que todas as escolas têm como prioridade de ensino as disciplinas de matemática e de português. Dos vários níveis de avaliação, talvez o mais injusto e desproporcional é a Provinha Brasil, porque é justamente nessa fase da escolarização que as crianças têm o direito se ser alfabetizadas na língua materna, que, no geral, nas escolas indígenas, não é o português. Então, como aplicar uma avaliação do desempenho em português se as escolas ensinam outras línguas, amparadas pela Constituição Federal?

As provas são aplicadas nacionalmente, não havendo diferenciação por regiões ou por contextos culturais específicos. Nessa dinâmica, as escolas indígenas são as mais prejudicadas, porque não são consideradas suas características próprias. $\mathrm{Na}$ medida em que uma escola indígena aplica pedagogicamente os conteúdos de seu interesse, respaldados pela legislação específica, estarão dando prioridade a outros conteúdos que não aqueles objetos da avaliação. Dessa forma, a avaliação não produz o efeito desejado, porque não se está avaliando o conteúdo aplicado, mas aquele desejado pelos gestores educacionais nacionais. Esses elementos remetem a questões prévias e basilares, como: Quem define a hierarquia dos conteúdos relevantes nas escolas indígenas a serem avaliados? Quem define que português e matemática são os conteúdos de interesse prioritário dos povos indígenas? Porque apenas a alfabetização na língua portuguesa é avaliada se, constitucionalmente, os povos indígenas têm direito à alfabetização na língua materna?

Para encontrar respostas a essas questões, faz-se necessário compreender que, para as sociedades ocidentais, a escola é uma instituição que ganha grande relevância na modernidade e se consagra como lugar social mais importante na socialização da pessoa, pois é onde são 
adquiridos os conhecimentos tidos como indispensáveis para a sua inserção no mundo do trabalho. Dessa forma, a organização curricular está estruturada de acordo com saberes consagrados e ordenados de um modo significativo para o mundo ocidental. A hierarquia de importância dos conteúdos ministrados produz uma valorização desigual dos saberes, sendo consideradas periféricas algumas dimensões que, na vida indígena, são centrais.

A avaliação, em última instância,éa aferição da capacidade de incorporação do conteúdo considerado mais relevante para os conhecimentos universais. Para o Estado brasileiro, o conteúdo relevante a ser avaliado é a língua portuguesa e a matemática, sendo, portanto, imputado aos povos indígenas a necessidade de aproximação dos saberes ocidentais, e, em última instância, a sua integração à sociedade nacional. $\mathrm{O}$ projeto de nação continua, portanto, sendo imposto aos povos indígenas. Em entrevista, Gersem Baniwa afirma que:

Quando observamos a difícil situação de vida dos povos indígenas, pelas permanentes violações de seus direitos básicos, como o direito ao território e à saúde, podemos acreditar que ou o Brasil ainda não definiu seu projeto de nação; ou já definiu e neste projeto não há lugar para os povos indígenas (PIMENTA, 2013).

Conforme mencionamos em nosso artigo anterior, constatamos que, de fato, não há um projeto de Brasil, mas sim um conceito de nação das elites dominantes. Nesse contexto, o lugar para os povos indígenas é o mesmo de duzentos anos atrás, quando se definiu simbolicamente a "nação" brasileira - ou seja, o não lugar. Os povos indígenas, porém, vêm modificando esse projeto e construindo outros. O fim jurídico da tutela, por exemplo, é um indicativo de que o projeto de nação das elites vem sendo questionado (BRIGHENTI, 2016).

\section{Considerações finais}

A qualidade da educação escolar passa necessariamente pela avaliação do seu sistema de ensino. Nesse sentido, a 
iniciativa do Ministério da Educação em criar mecanismos e aperfeiçoá-los é um ato necessário e fundamental para identificar as lacunas e melhorar o sistema educacional. A Portaria no 369 (BRASIL, 2016a), ao instituir o Sistema Nacional de Avaliação da Educação Básica, ampliou o alcance da avaliação para outras dimensões do ensino além das que ocorria o Saeb, porém manteve como base da avaliação as disciplinas de português e de matemática. Mesmo com as mudanças, não observamos uma avaliação geral, isto é, em todo o processo de ensino, que contemple as condições sócioculturais dos alunos e dos professores, as condições da escola (sua localização e sua estrutura física, por exemplo), a relação com a comunidade escolar e a construção de seus projetos político-pedagógicos. Tampouco há preocupação com outras dimensões do ensino, como as línguas, a história, e geografia regionais e as práticas corporais, dentre outras.

A busca da uniformidade através da matemática e do português está relacionada ao desejo de se criar, cada vez mais, mão de obra não pensante e pessoas que se ocupem do mundo do trabalho sem questioná-lo, atitude que poderíamos denominar "racionalidade técnica", que está atrelada ao conceito de qualidade, implicando criar indivíduos capacitados e aptos para o mundo do trabalho:

A racionalidade técnica vem sendo aplicada na política educacional brasileira, desde o período da ditadura militar, e vem se adaptando a cada contexto político-econômico, estabelecendo novas estratégias de ação. Entre elas, a atenção aos resultados, recomendada pelo Banco Mundial (BM), recebe destaque e a qualidade do ensino é aferida mediante a combinação dos resultados cognitivos (desempenho) com os de fluxo (aprovação, reprovação, evasão) no ínterim da política educacional brasileira. Ela está associada a um modelo de gestão consubstanciado em parcerias, tanto no plano intergovernamental quanto na intersecção entre o setor público e o privado, como nos casos de parceria entre o Instituto Ayrton Senna e as secretarias municipais de educação do país afora (SILVA, 2010, p.436). 
Além do exposto, para as escolas indígenas, o Sinaeb mantém os mesmos princípios de hierarquização de alguns conteúdos em detrimento de outro, impondo conteúdos relevantes para as sociedades ocidentais - por isso ditos universais - para populações que valorizam outros conhecimento, outros saberes.

As mudanças no Sinaeb, nesses mais de dez anos de processo de avaliação, não contemplaram a educação escolar diferenciada e não produziram parâmetros específicos para escolas específicas. Cria-se, assim, uma inversão, pois, ao mesmo tempo em que as comunidades conquistaram o direito de construir seus projetos político-pedagógicos, de definir os conteúdos relevantes e de aplicar suas próprias metodologias, elas são obrigadas a se submeterem às mesmas regras de avaliação de outros contextos, podendo inclusive serem penalizadas.

Importantes referenciais teóricos que nos auxiliam na compreensão do processo de imposição de um sistema escolar externo são os conceitos de colonialidade.O sociólogo peruano Aníbal Quijano (1992; 2009), a partir de estudos sobre o pensamento decolonial, elaborou o conceito de colonialidade do poder que nos ajuda a compreender como o projeto de colonização/dominação iniciado no século XVI pelos países europeus se perpetua até os dias atuais, tendo como principal executor e mantenedor dessa colonialidade o aparelho estatal. Para tanto, ele faz uma distinção entre colonialismo e colonialidade: o colonialismo refere-se à situação de dominação política, econômica e territorial de uma determinada nação sobre outra, de diferente território, a exemplo da colonização do Brasil por Portugal, das várias colônias espanholas na América Latina, das colônias inglesas na África, etc.; enquanto isso, a colonialidade, nas palavras do próprio Quijano (2009; p. 73),

é um dos elementos constitutivos e específicos de um padrão mundial de poder capitalista. Se funda na imposição de uma classificação racial/étnica da população do mundo como pedra angular daquele 
padrão de poder, e opera em cada um dos planos, âmbitos e dimensões, materiais e subjetivas, da existência cotidiana e da escala social.

A escola é uma instituição que ganha grande relevância na modernidade, em sociedades ocidentais, e se consagra como lugar social mais importante na socialização da pessoa e na aquisição dos conhecimentos tidos como indispensáveis para a sua inserção no mundo do trabalho. Assim, ela não apenas produz e socializa saberes, mas também produz experiências cotidianas que vão integrando a pessoa a uma lógica de sociedade e, ao mesmo tempo, vão produzindo o lugar social que esta pessoa irá ocupar. Assim, como a escola que temos está inserida em um modelo capitalista de produção, ela reproduz, dá coesão e torna significativo esse modelo, colaborando para desenvolver nos estudantes certas disposições, valores e anseios que são próprios desse tipo de sociedade (CIMI, 2014). Nela, a organização curricular está estruturada de acordo com saberes consagrados e ordenados de um modo significativo para o mundo ocidental. Quais são os conhecimentos que entram na escola? O que é considerado relevante? Quais disciplinas são mais valorizadas? As propostas das disciplinas escolares também produzem, em nossa cultura, uma valorização desigual dos saberes, sendo consideradas periféricas algumas dimensões que na vida indígena são centrais.

Portanto, a aplicação de um exame geral e universal implica dizer que o desejo último do Estado é a integração das populações indígenas na sociedade capitalista ocidental. Os povos indígenas vêm buscando dar outro rosto às escolas, modificando-as a partir da prática. A criação de mecanismos próprios de avaliação é um desejo e uma reivindicação desses povos, a fim de que os processos de avaliação ocorram no interior de cada escola e de cada povo e que os índices de aferimento sejam discutidos com as comunidades para perceber quais são os conteúdos prioritários, para identificar se as crianças estão sendo alfabetizadas na língua materna e não para impor o português e a matemática como elementos centrais. Resistir a esses projetos universalizantes e colonialistas é também 
dizer não. As notas baixas e os últimos lugares no Ideb são uma forma de dizer não à massificação das escolas. Portanto, enquanto persistir a prática universalista e colonialista, bemvindas asnotas baixas!

\section{Referências}

BERGAMASCHI, M. A. Tradição e memória nas práticas escolares Kaingang e guarani. Currículo sem Fronteiras, Porto Alegre, v. 10, n. 1, p. 133-146, 2010.

BORGES, L. F.P.; BORGES, P.H.P. O ensino da história nos referenciais curriculares nacionais para as escolas indígenas. [20--]. Disponível em: <http://djweb.com.br/historia/arquivos/ referenciaiscurriculares.pdf>. Acesso em: 26 out. 2016.

BRASIL. Constituição (1988). Constituição da República Federativa do Brasil. Brasília, DF: Senado Federal, 1988.

Ministério da Educação - MEC. Lei no 9.394, de 20 de dezembro de 1996. Estabelece as diretrizes e bases da educação nacional. Brasília: MEC, 1996.

- Ministério da Educação - MEC. Referencial Curricular Nacional para as Escolas Indígenas (RCNEI). Brasília: MEC, 1998.

- Ministério de Educação - MEC. Conselho Nacional de Educação - CNE. Parecer no 14, de 14 de setembro de 1999. Brasília: MEC, 1999a.

- Ministério de Educação - MEC. Conselho Nacional de Educação - CNE. Resoluçáo no 3, de 10 de novembro de 1999. Fixa Diretrizes Nacionais para o funcionamento das escolas indígenas e dá outras providências. Brasília: MEC, 1999b.

Convençáo no 169 da Organizaçáo Internacional do Trabalho. Brasília: OIT, 2002.

. Ministério da Educação - MEC. Portaria no 931, de 21 de março de 2005. Institui o Sistema de Avaliação da Educação Básica SAEB. Brasília: MEC, 2005.

- Ministério de Educação - MEC. Instituto Nacional de Estudos e Pesquisas Educacionais Anísio Teixeira- INPEP. Censo escolar. Brasília: MEC, 2007a.

. Ministério da Educação - MEC. Decreto no 6.317, de 20 de dezembro de 2007. Reestrutura o Ideb. Brasília: MEC,2007b. 
- Ministério de Educação - MEC. Instituto Nacional de

Estudos e Pesquisas Educacionais Anísio Teixeira- INPEP. Censo escolar. Brasília: MEC, 2014.

Ministério da Educaçáo -MEC. Portaria no 369, de 5 de maio de 2016. Institui a Avaliação Nacional da Educação Básica (Aneb). Brasília: MEC, 2016a.

Ministério da Educação - MEC. Base nacional comum curricular. 2. ed. rev.. Brasília. MEC, $2016 \mathrm{~b}$.

Ministério da Educação - MEC. Ministério da Educação. Brasília, 2016c. Disponível em: <http://portal.mec.gov.br/index.php>. Acesso em: 12 de nov. 2016.

BRIGHENTI, Clovis A. Colonialidade e decolonialidade no ensino da história e cultura indígena. In: SOUZA, Fábio Feltrin de; WITTMANN, Luisa T. (Org.). Protagonismo indígena na História. Tubarão, SC: Copiart; Erechim, RS: UFFS, 2016. p.231-254.

CIMI. Por uma Educaçáo Descolonial e Libertadora: Manifesto sobre a educação escolar indígena no Brasil. Brasília: Cimi, 2014.

PIMENTA, Thiago. Atual projeto de nação não tem lugar para povos indígenas, diz indígena e doutor em antropologia. EBC. Brasília, 13 abr. 2013. Disponível em: <http://www.ebc.com.br/ cidadania/2013/04/indigena-e-doutor-em-antropologia-social-falasobre-projeto-indigenista-para-o >. Acesso em: 10 jul. 2015.

QUIJANO, Aníbal. Colonialidad y Modernidad-racionalidad. In: BONILLO, Heraclio (Comp.). Los conquistados. Bogotá: Tercer Mundo Ediciones; FLACSO, 1992. p. 437-449.

Colonialidade do poder e classificação social. In: SANTOS, B. S.; MENESES, M. P. (Org.). Epistemologias do Sul. Coimbra: Ediçóes Almedina. SA, 2009.

SILVA, Isabelle Fiorelli. O sistema nacional de avaliação: características, dispositivos legais e resultados. Revista Est. Aval. Educ., São Paulo, v. 21 , n. 47 , p. 427-448, set./dez. 2010.

Submetido em: 18/11/2016

Aprovado em: 14/12/2016 


\title{
CHALLENGES FOR SPECIFIC SCHOOL EDUCATION IN UNIVERSALIZING POLICY CONTEXTS
}

\begin{abstract}
In this article we develop a critical analysis of the education system in terms of universalizing policies and challenges for the specific and differentiated education, conquered by the indigenous peoples. To the extent that these specific rights have been extended reading and becoming reality, the Ministry of Education has created various mechanisms that circulate in the opposite direction, valuing and requiring knowledge of universal knowledges. As an example, we take the data collected by the Index of Development of Basic Education (Ideb)on evaluation of indigenous schools in Santa Catarina in 2011 and 2013 and found that they were among the worst placements in that state. We seek to understand the methodology and ideology that guide the evaluations. We realize that there is imposition of content and methodologies practices. The evaluation without respecting the particularities remains a way of imposing on indigenous integrating the "nation" Brazilian. From the concepts of colonialism, we conclude that to persist this evaluation model the low notes are forms of resistance.
\end{abstract}

Keywords: Education.Assessment. Resistance. 